\title{
BMJ Open Qualitative study on voyaging and health: perspectives and insights from the medical officers during the Worldwide Voyage
}

\author{
Marjorie K Leimomi Mala Mau (D) , ${ }^{1}$ Christina Mie Minami, ${ }^{1}$ Sarah A Stotz, ${ }^{2}$ \\ Cheryl L Albright, ${ }^{3}$ Shawn Malia Kana'iaupuni, ${ }^{4,5}$ Heidi Kai Guth ${ }^{1,6}$
}

To cite: Mau MKLM,

Minami CM, Stotz SA, et al. Qualitative study on voyaging and health: perspectives and insights from the medical officers during the Worldwide Voyage. BMJ Open 2021;11:e048767. doi:10.1136/ bmjopen-2021-048767

- Prepublication history and additional supplemental material for this paper are available online. To view these files, please visit the journal online. To view these files, please visit the journal online (http://dx.doi. org/10.1136/bmjopen-2021048767).

Received 07 January 2021 Accepted 18 June 2021

Check for updates

(C) Author(s) (or their employer(s)) 2021. Re-use permitted under CC BY-NC. No commercial re-use. See rights and permissions. Published by BMJ.

For numbered affiliations see end of article.

Correspondence to Dr Marjorie K Leimomi Mala Mau; mmau@hawaii.edu

\section{ABSTRACT}

Objective To examine the potential association of ocean voyaging with human health and well-being from the perspectives and experiences of the medical officers (MOs) who served during the Worldwide Voyage (WWV).

Design Using a phenomenology framework, focus group and individual interviews were conducted and analysed by three diverse core researchers and then reviewed by three external researchers to enhance triangulation. Analysis used the Framework Method and Atlas-ti software (V.8.4.4) to facilitate coding, identify categories and develop an analytical matrix. The matrix was applied to all data using the constant comparative method to construct major themes and subthemes. Synthesised member checking was performed. Setting In 2014-2017, the WWV began in Hawai'i on a traditional voyaging canoe, known as $H \bar{k} k \bar{l} l e^{\prime} a$, using a non-instrument navigational method, 'wayfinding', powered only by natural forces and guided by traditional ecological knowledge. Each segment of the voyage included 12 individuals, including an M0 physician. The entire WWV included 172 ports-of-call, 36 legs and 250+ crew members.

Participants We purposively sampled all MO physicians who participated in the WWV and enrolled $87 \%$ of eligible MOs ( $n=20$ of 23). We conducted two focus groups $(n=17=11+6,85 \%)$ and three individual informant interviews $(n=3,15 \%)$.

Results The four major themes: (1) Relationships; (2) Preventive Care to Enhance Health; (3) Holistic Health and Wellbeing beyond Voyaging and (4) Spiritual Transformative Experience, strongly suggest that ocean voyaging aboard a traditional voyaging canoe enhanced human health and well-being. The overall impact to perceived health and wellbeing extended beyond any increase in physical exercise. Essentially, traditional Polynesian ocean voyaging provided a cultural-based context for holistic health and well-being that influenced multiple levels and multiple dimensions. Conclusion Polynesian ocean voyaging was perceived as positively associated with holistic health and overall well-being and it may offer a new approach to confront complex health disparities.

\section{INTRODUCTION}

Native Hawaiians (NHs) and Pacific Islanders (PIs), including Polynesians,
Strengths and limitations of this study

- A major strength is the systematic analytical approach of the Framework Method followed by group member checking of $95 \%$ of the participants to validate and strengthen the final results.

- This is also the first research study conducted to understand the impact of ocean voyaging, a culturalbased physical activity, on human health and well-being aboard traditional Polynesian voyaging canoes.

- Results provide a deeper understanding of the socioecological underpinnings of ocean voyaging to holistic health and well-being and may offer novel insights into reducing modifiable health behaviours and other risk factors associated with cardiometabolic health disparities.

- A study limitation was the enrolment of only medical officers for this initial study. However, we intentionally chose to select the medical officers as astute observers best positioned to provide an objective assessment of overall health and well-being of the crew as well as themselves.

Melanesians and Micronesians, share a common ancestry as the original peoples who discovered, settled and first inhabited the islands dispersed throughout Oceania, beginning as early as $900 \mathrm{AD} .^{1-3}$ These Indigenous peoples of Oceania lived in accordance with their surrounding environment. Based largely on an ocean existence, Native Hawaiians and Pacific Islanders (NHPIs) developed a profound knowledge and understanding of climate patterns, celestial bodies and natural forces that were integrated into a mastery of skills to formulate a non-instrument navigational method known as 'wayfinding'. ${ }^{3-5}$ This ancestral knowledge of wayfinding sustained the cultural practice of ocean voyaging across the vast Pacific region and has remained largely unknown to western civilisation over the last 2000 
years. ${ }^{16}$ Ancient Polynesians, as expert canoe builders and master wayfinders, navigated the vast Pacific Ocean to explore and settle the 10-million-square-miles of the Polynesian Triangle aboard traditional doublehulled canoes (wa'a kaulua, in $\mathrm{NH}$ ) repeatedly and with intentional purpose. ${ }^{7-9}$ European explorers from England, France, Spain among others, were late comers to the Pacific region, arriving in successive waves from the early 1500s, including ships from the USA to the northern archipelago of Hawai'i up until the 1900s. ${ }^{10}$ These countries would eventually colonise many remote island outposts on behalf of foreign interests, and the resulting changes in political leadership led to permanent changes in the lives and livelihoods of generations of peoples throughout Oceania, including NHs. ${ }^{11}$ In Hawai' $i$, the illegal overthrow of the Hawaiian kingdom in 1893 by the USA resulted in dispossession of the NH kingdom and its land assets and a suppression of $\mathrm{NH}$ cultural identity, language, beliefs and practices. ${ }^{10} 12$ Although political changes in Hawai'i benefited many new residents, the NH population experienced displacement from their ancestral homelands, racial discrimination and lower educational attainment, which often resulted in economic poverty. ${ }^{10} 12$ These adverse social determinants of health persist today, often leading to higher morbidity and mortality across the NH lifespan, relative to other racial/ethnic groups. ${ }^{13-15}$

Today, NHPIs endure a disproportionate burden of health disparities, especially among cardiometabolic diseases such as diabetes mellitus (DM), cardiovascular disease (CVD) and stroke (cerebrovascular accident, CVA) ${ }^{16}$ These health disparities are known to occur 10-15 years earlier in life ${ }^{16-18}$ and predispose NHs to increased morbidity and mortality compared with USA whites. ${ }^{13} 19$ Obesity/overweight, a major risk factor for cardiometabolic morbidity, is prevalent in $\sim 85 \%$ of the NHPI adult population and $\sim 20 \%$ of NHPI children starting at birth, and is predictive of obesity in young adulthood. ${ }^{20-24}$ Indeed, two recent studies have suggested a significant association between cardiometabolic disorders (obesity, DM2, cardiomyopathy) and genomic variants as well as lifestyle factors among NHPI adults. ${ }^{25}{ }^{26}$ Lifestyle behaviours, especially dietary intake and physical activity, are well established first-line therapies for mitigating obesity-associated cardiometabolic diseases. ${ }^{27-29}$ However, few studies have carefully studied the exercise regimens or physical activity behaviours relative to NHPIs, a population at increased risk for obesity-related health disparities. This paucity of evidence is further confounded by epidemiological studies reporting that more than 50\% of NHPI youth and adults meet or exceed public health recommendations for physical activity goals (ie, $150 \mathrm{~min}$ of moderate-to-vigorous physical activity per week). ${ }^{30}$ This apparent paradox has prompted further investigations into studies exploring specific types of exercise (eg, strength, resistance, aerobic), dose or format, as well as cultural factors that may advance our current understanding of exercise and obesity-related diseases in a

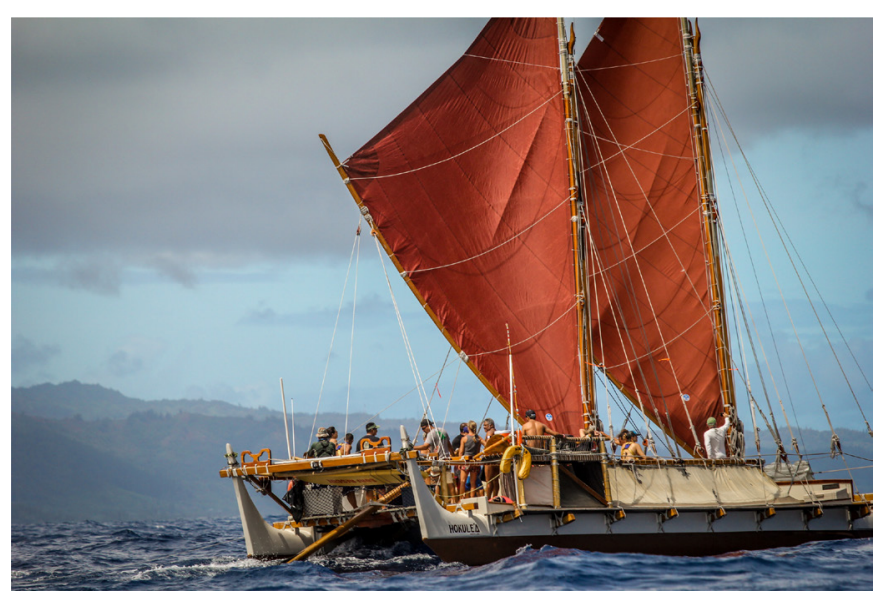

Figure 1 Photo of Hōkūle‘a under traditional crab-claw sail off $\mathrm{O}^{\prime}$ ahu, Hawai'i. She is 62 feet long and 23 feet wide, with 300 square feet of deck space for an average crew of 12 people. All food and water is stored in the hulls, where crew also sleep under the tan canvas covers. The total covered area for people to sleep-head to toe-is approximately 138 square feet. Solar panels power safety elements of maritime lights and radios. She has no engines, refrigeration, nails or screws; approximately 5 miles of rope lash her together and at least 2 miles of line make up her rigging. Copyrighted photo courtesy of Polynesian Voyaging Society and 'Ōiwi TV.

growing sector of diverse populations in the USA, such as NHPIs. ${ }^{30} 31$

In 2013, a team of Hawai' i-based researchers examined specific forms of physical activity drawn from the cultural practices of NHPIs in the form of hula, an NH-Polynesian cultural form of dance. Working collaboratively, hula experts and scientists determined that the practice of hula expended 5.7-7.6 METs (metabolic equivalents of physical exertion) under standardised measurements. ${ }^{32}$ That is, the physical exertion of hula was similar to a halfcourt game of basketball (MET-value 7.6 METs). ${ }^{32}$ In a companion experimental study, the authors also found that a hula intervention programme significantly reduced diastolic blood pressure providing preliminary results on the positive impact of hula on CVD risk factors that may benefit the larger NHPI population at increased risk. ${ }^{33}$

Within this context, Polynesian ocean voyaging is also a cultural-based, physical activity and involves open-ocean sailing aboard traditional, double-hulled canoes powered only by natural forces (wind and waves), and using only noninstrument navigation. ${ }^{54-38}$ The ancestral knowledge and practice of ocean voyaging is another cultural-based physical activity unique to NHPIs and practiced throughout Oceania. ${ }^{534-38}$ In 1973, the Polynesian Voyaging Society (PVS), a non-profit organisation based in Hawai'i, launched Hōkūle' $a$, meaning 'Star of Gladness' and the $\mathrm{NH}$ name for Arcturus, a key navigational star which rises directly over Hawai'i. In 1976, Hōkūle'a (figure 1) was also the first traditional wa'a kaulua (voyaging canoe) to have sailed within Polynesia using ancestral knowledge in more than 600 years. ${ }^{53739}$ Thus, PVS is often credited with being a catalyst of the $\mathrm{NH}$ cultural renaissance movement 
that began in the 1970 s and continues today. ${ }^{3940}$ Over the years, PVS has remained a community organisation that, with more than a thousand volunteers, planned and successfully completed the Worldwide Voyage (WWV) in 2014-2017. ${ }^{40}$ PVS sought to learn from other indigenous, island and coastal people about local solutions to global ecological and social challenges, and to use Hōkūle $a$ as a 'floating classroom' of Hawaiian values and as a model for island sustainability. ${ }^{35} 4041$ The WWV began and ended in Hawai' $i$, after logging 190000 nautical miles, visiting 172 ports in 23 countries and territories, and completing 36 legs (segments that allowed for crew changes every $~ 33$ days), with more than 250 crew members. Each WWV leg included a licensed physician serving as the medical officer (MO) onboard who was responsible for the health and well-being of the crew members. To date, the WWV serves as the longest voyage of any Polynesian voyaging canoe in recorded history. ${ }^{40}$

During more than 46 years since Hōkūle'a's maidenvoyage, PVS crew members have reported anecdotal health benefits. ${ }^{42-44}$ Unfortunately, few studies have rigorously examined the potential relationship between voyaging and health, in part, due to ocean voyages of limited scope and enlisted crew members. The WWV provided a unique opportunity and context to examine whether active participation in ocean voyaging influences human health and well-being. We chose to undertake this study by interviewing the MOs because of their specific role during the voyage and their responsibility to assess the health and well-being of the crew. Thus, the purpose of this qualitative study is to examine the potential association of ocean voyaging with human health and wellbeing, from the perspectives and experiences of the MOs who served during the WWV.

\section{METHODS}

\section{Participants}

How physicians were selected as M0s

The selection of MOs who served during the WWV was determined by PVS leadership and their associate voyaging organisations known as the 'Ohana Wa'a (meaning the Canoe Family). Collectively, these organisations have more than 35 years of cooperative ocean voyaging and careful construction of compatible groups of crew members, including an appropriate MO. The MO selection process included an initial interview by one veteran MO, who provided recommendations to PVS leadership, which made the final selection. Multiple factors were considered: (1) dedication to the voyaging community (ie, years of service), (2) value added to the crew and mission (ie, multiple skill sets), (3) cultural value (ie, to mission or landfall), (4) medical expertise (ie, physician trained) and (5) availability to voyage (ie, time away from work). The final MO selection was also contingent on the MO-candidate completing all physical fitness requirements and medical clearance, as was required by all crew.
A total of 23 MOs were deployed during the 3-year WWV journey. The total group of MOs $(n=23)$ also included one land-based physician with $10+$ years of MO-voyaging experience who served as the 'chief' MO in charge of organising medical supplies and coordinating prevoyaging medical assessments of all crew members. All MOs were advised to prepare for and complete a minimum of ocean voyaging and sailing training, possess familiarity with common medical conditions at sea, and prepare for public health conditions at various landfalls for their assigned segment. As active crewmembers, they carried out standard crewmember tasks and duties, such as raising sails, bailing water from the hulls, tying sailing knots, cooking, cleaning and so on. Thus, the WWV MOs were active participants during ocean voyaging and this enabled personal observations of how voyaging affected themselves and their crewmates. To examine these perspectives and experiences, all WWV physician MOs were invited (total MO eligible $=23$ ) to participate in scheduled focus groups and interviews conducted in Honolulu, Hawai'i approximately 1 year following the end of the WWV in 2017. A total of 20 (87\%) MOs volunteered for either focus group $(n=17)$ or individual informant $(n=3)$ interviews.

\section{Ocean voyaging experience of $\mathrm{M} 0$ participants}

Each MO served on a leg of the WWV as the only physician aboard. Each leg of the voyage provided a unique set of voyaging circumstances such as weather conditions, crew members, leadership (captains), land destinations, cultural context and so on. Each leg also included certain types of voyaging days (ie, deep ocean, inter-island or coastal voyages) which required a range of physical and mental endurance (PME) levels of all of the crew, including the MO. To approximate the level of PME on each leg, we weighted each of the legs of the WWV by type of ocean voyaging days and adjusted the number of days on that leg by a PME factor. 'Deep Sea' voyaging days were considered voyaging that required the highest PME and was assigned a PME factor of 1.0. 'Inter-island' voyaging days required moderate PME and 'Coastal' voyaging required lower PME. Those voyaging days were adjusted by multiplying those voyaging days by PME factors of 0.8 and 0.6 , respectively (figure 2 ).

\section{Data collection}

\section{Focus group and individual informant interview format}

Two focus groups were completed with 11 and 6 participants, respectively. Due to scheduling conflicts, $3 \mathrm{MOs}$ were interviewed individually for a total of $20 \mathrm{MO}$ participants. All focus group and individual informant interviews used a narrative 'talk story' format consistent with local NHPI norms to create a safe cultural context to express personal opinions and insights. ${ }^{45} 46$ All interviews occurred face-to-face with the exception of three participants who, due to travel constraints, participated via live video tele-conferencing. The interviewer guide included five open-ended questions with additional probes aimed 
Figure 2: Summary of Ocean Voyaging Experiences by Medical Officers $(n=20, W W V, 2014-2017)$

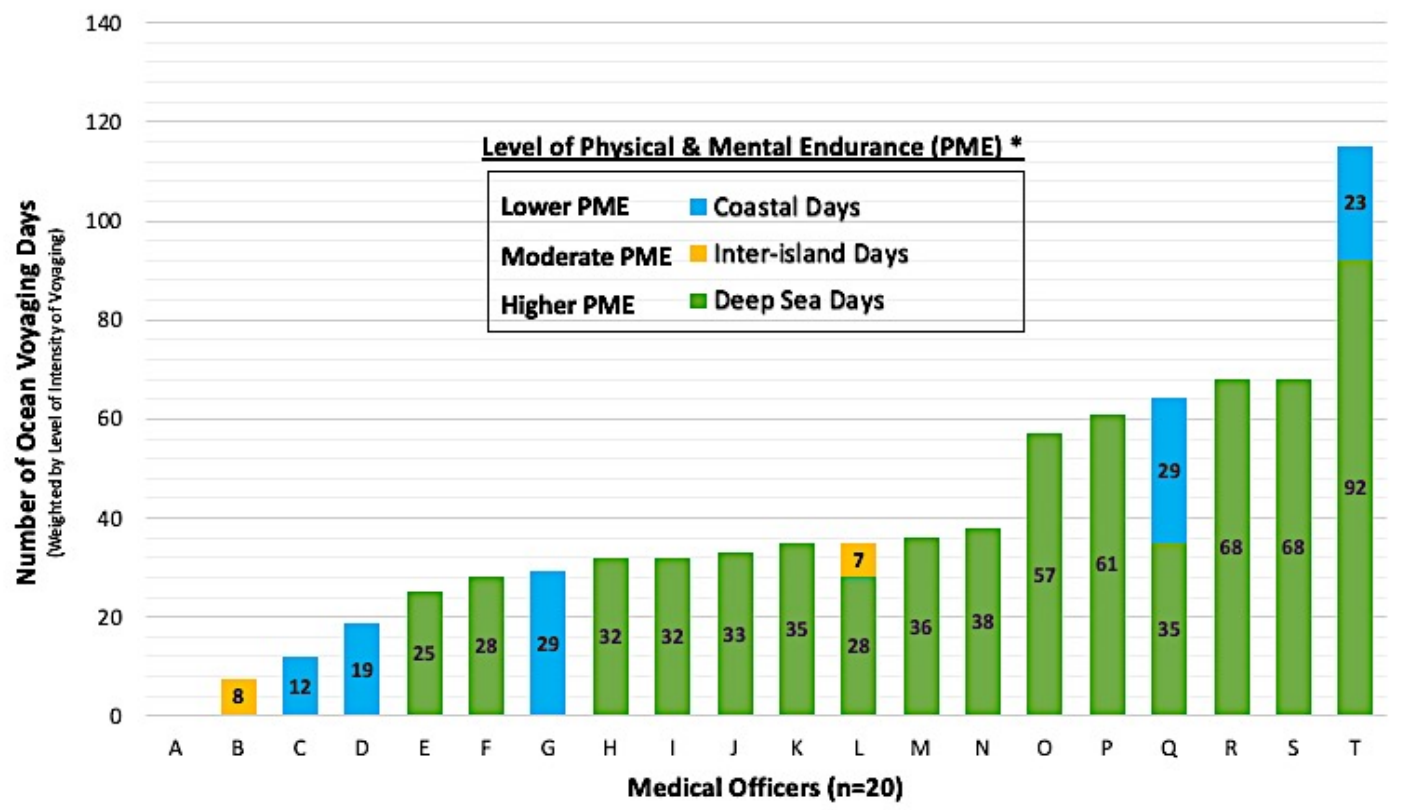

Figure 2 Summary of ocean voyaging experiences by medical officers ( $n=20$, Worldwide Voyage, 2014-2017). *Ocean voyaging days were weighted according to level of physical and mental endurance (PME) defined as Coastal days=\#days $\times 0.6$; Inter-island days=\#days $\times 0.8$; Deep Sea days=\#days $\times 1.0$.

at soliciting further insights to personal or observed experiences on ocean voyaging and aspects of health and wellbeing. ${ }^{47}$ The interviewer guide was identical across all interviews (group or individual), with each session lasting 120-150 min in length (online supplemental Moderator Guide). All interviews were audio recorded and transcribed verbatim by a professional transcriptionist. The written transcripts were then checked by one of the three researchers for accuracy (grammar, spelling), cultural context, Hawaiian language and nautical terms, and crosschecked with field notes taken by a designated notetaker or the interviewer/moderator. To ensure anonymity, all participant names were redacted and replaced with preassigned pseudonyms at the time of transcription (figure 3, stage 1). All audio tapes were destroyed following the two-step review for accuracy and privacy concerns. All participants completed a brief demographic and medical professional background questionnaire at the end of the session (online supplemental MO questionnaire).

\section{Patient and public involvement}

This study involved enrolling physician-MOs who participated in the WWV in 2014-2017. Thus, patients were not enrolled or involved with the study. Physician-MO participants were invited to provide feedback on the purpose of the study, verify results and interpret the summarised findings through a participant (ie, member) checking process. Their feedback and comments are included in the final manuscript.

\section{Analysis}

Transcription data were analysed by three primary researchers using the Framework Method (figure 3), a systematised thematic analysis method. ${ }^{48}$ The three primary researchers represented a diverse and balanced team in terms of voyaging experience, age, and familiarity with NHPI culture. Each of the researchers were encouraged to voice their individual perspective to the data analysis and coding discussions throughout the analytical process. The Framework Method allowed for a common understanding of a stepwise approach, resulting in a systematic method to generate emerging categories, major themes and subthemes. ${ }^{48}$

During stage 2, each researcher independently reviewed the written transcripts to familiarise themselves with content, patterns and individual quotes and uploaded them into Atlas.ti (Mac V.8.4.4) for coding, data management and analysis. ${ }^{49}$ The three researchers independently and inductively coded key quotations in the transcript of the first focus group (stage 3) and subsequently met to discuss any differences in coding or interpretation until consensus was reached. Codes were merged based on frequent comparisons, debate and open discussion on the interpretations of data to create a working analytical framework ('codebook'), with code names and definitions (stage 4). Researchers used this codebook to apply the analytical framework to the second focus group and the three individual interview transcripts. New codes 


\section{Figure 3: Approach to Qualitative Content Analysis Process using the Framework Method}

\section{Stage 1: Transcription}

All interviews were transcribed verbatim by a commercial transcription service familiar with health and medical terminology and deidentified

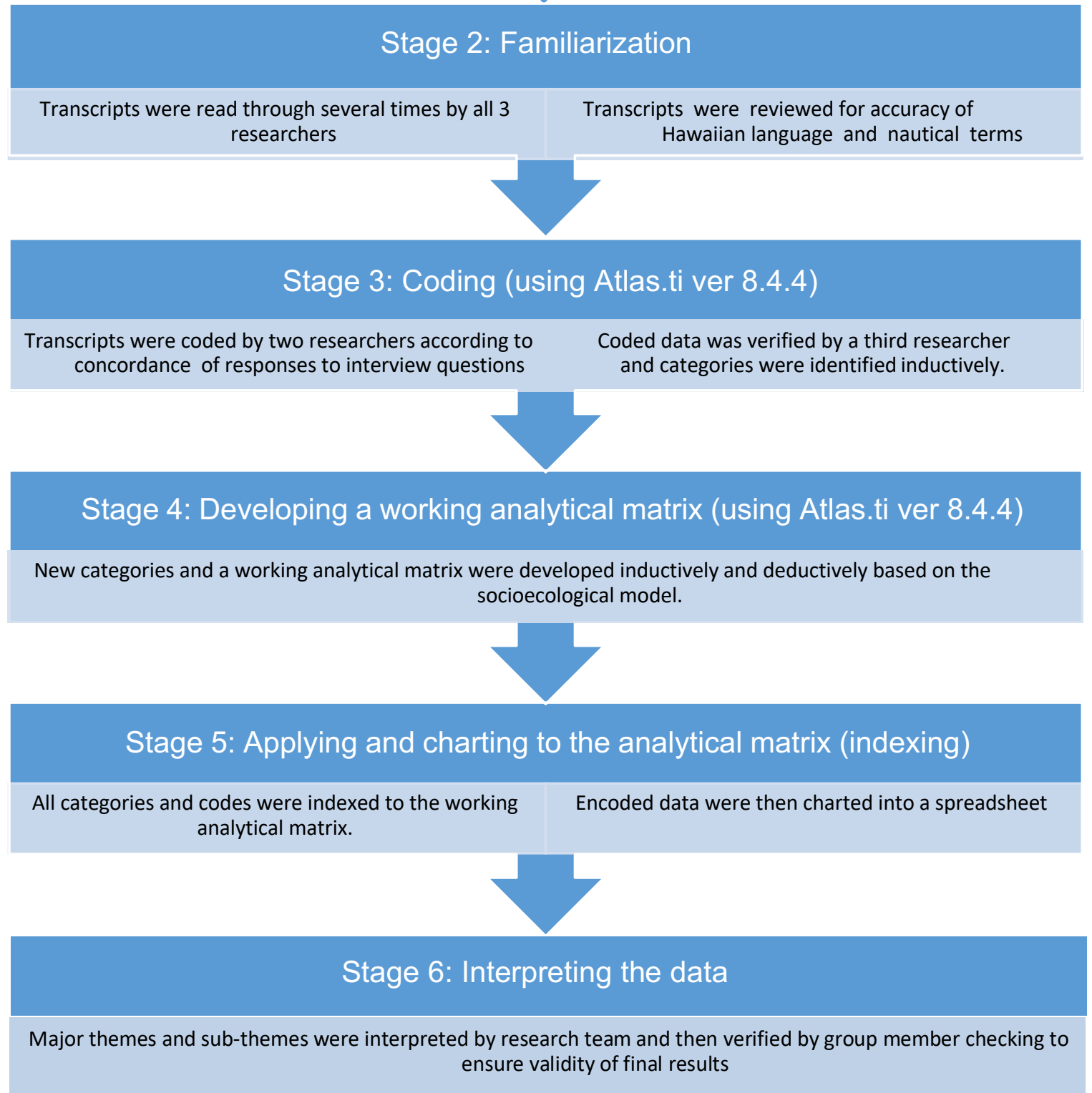

Figure 3 Approach to qualitative content analysis process using the Framework Method.

and definitions were determined jointly by the three researchers who collectively refined the coding system using a constant comparative method until consensus was achieved to create the final 'codebook'. 5051 Codes were then organised into overarching 'categories'. Data were charted into a framework matrix, where each sheet represented a category, with its codes and corresponding quotes (stage 5). ${ }^{48}$ As the final step in analysing the data, each code and their exemplary quotes were used to develop a category definition. Researchers then grouped the categories by related components within their definitions and quotes into the final development of the major themes and subthemes or categories (figure 3, stage 6 ). To verify data interpretation and results, we convened a memberchecking group interview with 19 of the 20 participants approximately 1-2 years following their original interview (group or individual). ${ }^{52}$ Their feedback and comments 
Table 1 Characteristics of physicians who served as medical officers during the Worldwide Voyage, 2014-2017 $(\mathrm{N}=20)$

\begin{tabular}{|c|c|}
\hline Characteristic & $\mathrm{n}(\%)$ or mean (SD, range) \\
\hline Age* (Years) $^{*}$ & $\begin{array}{l}60.9 \text { year } \\
\text { (minimum 44, maximum } 74 \text { ) }\end{array}$ \\
\hline Women & $8(40 \%)$ \\
\hline \multicolumn{2}{|l|}{ Marital status } \\
\hline Married & $80(\%)$ \\
\hline \multicolumn{2}{|l|}{ Race/ethnicity } \\
\hline Native Hawaiian & $8(40 \%)$ \\
\hline Caucasian & $6(30 \%)$ \\
\hline Filipino & $2(10 \%)$ \\
\hline Pacific Islander (Samoan) & $1(5 \%)$ \\
\hline Japanese & $1(5 \%)$ \\
\hline West Indian & $1(5 \%)$ \\
\hline Armenian & $1(5 \%)$ \\
\hline \multicolumn{2}{|l|}{ Medical training } \\
\hline Internal medicine (IM) & $6(30 \%)$ \\
\hline $\begin{array}{l}\text { Double board-certified in } \\
\text { subspecialty plus } \mathrm{IM}^{\dagger}\end{array}$ & $3(15 \%)$ \\
\hline Family medicine & $5(25 \%)$ \\
\hline Emergency medicine & $2(10 \%)$ \\
\hline $\begin{array}{l}\text { Preventive or functional } \\
\text { medicine }\end{array}$ & 2 (10\%) \\
\hline Paediatrics & $1(5 \%)$ \\
\hline Ophthamology & $1(5 \%)$ \\
\hline
\end{tabular}

${ }^{*}$ Age at time of focus group.

†Internal medicine additional subspecialties: neurology $=1$; endocrinology $=1$, paediatrics $=1$.

were discussed and were incorporated into the overall analysis and final interpretation.

\section{RESULTS}

The participants in this study were all well-established medical practitioners with several years of experience in clinical practice and specialty care, ranging in ages from 44 to 74 years (mean age 61 years), and with current medical board certification as active clinical practitioners (table 1 ). Forty per cent ( 8 of 20 ) of the MOs were women, $80 \%$ married and nearly half $(45 \%, 9$ of 20$)$ were of NH or Pacific Island ancestry (Samoan). The majority of MOs were non-white $(70 \%)$ mirroring the State of Hawai'i's multi-ethnic population $(\sim 80 \%$ non-white or mixed racial/ethnic background), where most of the MOs reside and were recruited from. Most of the MOs specialised in adult primary care medical practice such as internal medicine $(30 \%)$ or family medicine $(25 \%)$, and three were dual-boarded in more than one specialty. Two physicians were emergency medicine $(10 \%)$ and two preventive/functional medicine (10\%) trained (table 1).
Many of the physicians in this study served on more than one leg and $75 \%$ served on a 'Deep Sea' leg described as voyaging days with the highest PME (figure 2). Nine (45\%) of the physicians served as MO for $\sim 1$ month (28-38 days), $6(30 \%)$ served $\sim 2$ months (57-68 days) on the canoe, and one MO served for more than 4 months (123 days) (figure 2). A few MOs $(n=3)$ had prior or current maritime experience (ie, actively sailed on private boats, or held merchant sea captain license, etc), however, they were the exception, as most MOs were novice to open ocean voyaging.

\section{Themes and subthemes}

Four major themes emerged on the concept of ocean voyaging and human health and well-being. These four themes include: (1) Relationships; (2) Preventive Care to Enhance Health; (3) Holistic Health and Wellbeing beyond Voyaging and (4) Spiritual Transformative Experience (see table 2 for illustrative quotes). The 4 major themes and 16 subthemes are given in the following sections.

\section{Theme \#1: Relationships}

Description-building relationships before, during and after the voyage was described as a novel, positive, closeknit and motivating opportunity for people to put aside differences to accomplish common goals for the benefit of everyone. These relationships occurred across diverse communities, groups and individuals and enabled the learning of life values, provided leadership role models and created effective relationships to ensure health and well-being.

The concept of Relationships was perceived as foundational to the health benefits of ocean voyaging. At multiple levels, relationships were interdependent and provided meaningful, reciprocal social interactions that continued even after the voyaging leg was completed. The four subthemes include: (1) Community Relationships; (2) Crew Relationships; (3) Voyaging Leadership and (4) Medical Officer Relationships (table 2: theme \#1).

\section{Theme \#2: Preventive Care to Enhance Health}

Description - health enhancing care was enabled while voyaging by changes in physical activity, dietary intake, crew attitudes and cultural mindfulness. MOs supported health enhancement by preventive health education, using both traditional healing and allopathic medical care.

This theme also describes MOs having to prepare themselves to serve in the role of MO and not in their typical role as a physician-in-charge. This role change on the canoe had high agreement among participants and enabled crew preferences for non-allopathic therapies such as NH traditional medicines for minor ailments. Four supporting subthemes include: (1) Physical Movement; (2) Mental Focus; (3) Preparation and (4) Medical Officer Provider Role (see table 2: theme \#2). 
Table 2 Summary of medical officers' (MOs') insights and perspectives on voyaging and health $(\mathrm{N}=20)$

\section{Themes}

1. Relationships: building relationships before, during and after the voyage was described as novel, positive, close-knit and motivating for people to put aside differences to accomplish common goals for the benefit of everyone. These relationships occurred across diverse communities, groups and individuals and enabled the learning of life values, leadership role models and effective relationships to ensure health and well-being.

Subthemes Illustrative quotes

Community relationships Voyaging promotes heightened awareness about community interdependence.

- '... wherever ... [communities] ... were coming from, it was ... a poor area, and each of their trucks were just full of fruits and things ... and [they] came down and ... started loading all the fresh fruit for us. In that moment you realize that poor people are giving to you'.

- 'The crux of managing the canoe ... build[ing] the canoe, how you repair it, each of those tasks is involved in perpetuating voyaging as well as ... education [elementary, public school, private, charter, higher education] ... all of those elements are involved'.

Crew relationships

Being a crewmember teaches one how to be a family at sea, always protecting each other's wellbeing.

- '... Being a part of a team. I'll say that I never felt safer than when I'm on the canoe and with the crew. Even when we go on land, being part of that crew is a sense of safety ... It's a life team'.

- 'It's not every group that l'd just drop everything l'm doing at a moment's notice and go and do that. So that is certainly one thing about this crew. If they call you go'.

Voyaging leadership Leadership (ie, captains) served as role models of how effective relationships work on-board and in
life.

Medical officer relationships

Successful medical officers are those that build and nurture relationships with mutual respect as part of their role to care for the crew.

- '... we actually became much better observers ... Because they didn't tell us anything ... "So what's going on[?]" ... and then they'd finally [say] "Oh yeah, well,[o]k, l'll talk to you now". So, we actually became better physicians'.

2. Preventive Care to Enhance Health: health enhancing care was enabled while voyaging by changes in physical activity, dietary intake, crew attitudes and cultural mindfulness. MOs supported health enhancement by preventive health education, using both traditional healing and allopathic medical care.

Subthemes
$\begin{aligned} & \text { Physical movement } \\ & \text { Illustrative quotes }\end{aligned}$
'It's good for balance and you're constantly climbing over all kinds of obstacles or going out
on the hull and pulling things and using muscles you haven't used in years and years. It's both
aerobic and isometric at the same time so it's good for your heart and good for your muscles,
good for joints and flexibility'.
A change of perspective and being present in the moment at all times improves mental health.
'It is definitely a remov[al] from normal life, which is something we all should do, probably as
often as we can ... and it gives you perspective on it'.
'I would just say that I'm more patient and tolerant of those around me and things that maybe
don't go right. It's okay, we'll fix it later or we'll manage'.
The well-being journey begins through physical and mental preparation long before the day you set
sail. 'This was the first time that being physically in shape was going to get me something I wanted'.
Culturally, voyagers use diverse strategies to manage their physical wellness.
Medical officer provider $\quad$ '... we used a lot of la'au [traditional Native Hawaiian medicines] ... The crew preferred to use
role
on them] ... before I started dispensing cold medicines. That was a really neat addition to have
better - that they have this other sort of toolbox that they could go to as well'.

3. Holistic Health and Wellbeing beyond Voyaging: the experience of voyaging improved holistic health and well-being across multiple dimensions and multiple levels over time. Immersion in the voyaging experience enabled changes to individuals' physical, mental and emotional health, cultural and social interactions, and awareness of and direct influence by the natural environment and spiritual experiences.

Subthemes Illustrative quotes


Table 2 Continued

\section{Themes}

Overall well-being

Changes in well-being are multi-dimensional-physical, mental, emotional and spiritual.

- ... I was at a point in my life where I was really struggling for challenge, for purpose, for meaning for belonging. ... something ... I could really commit myself to. ... It's been ... 3 years ... since I was on the canoe. ... [and] it's amazing ... that sense of health and wellbeing ... has really stayed with me. ... [voyaging] has ... a tremendous ability to enhance people's health and wellbeing ... psychological-[well]being ... [a]nd the physical wellbeing follows.'.

Physical health

MOs observed improvement in physical activity, sleep and metabolism.

- 'On the canoe, you're never sedentary ... Even when you're sleeping, you're rocking back and forth. If you're sitting on the nets, you're doing crunches all day. And you're using a completely different set of muscles; you're using core muscles. It's balance ... using totally different muscles that you would never use on a day-to-day basis on stable land'.

$\begin{aligned} & \text { Mental and emotional } \\ & \text { health }\end{aligned}$
Spiritual connection
Spiritual clarity and belonging are keenly felt as positive health effects when at sea.
'I found peace I think out on the water. There's a lot of commotion in the life of a physician and a
lot of things pulling at you and so there's this sense of peace looking at the changing sky and the
water ...'.
Improved well-being includes a deeper kinship with and respect for nature.
'[The idea that we, the humans on the canoe, need to be respectful and collegial and interacting
and helping each other ... it's actually true in the larger sense also. The creatures around us and
honestly the currents and waves and wind around us ... are all part of the whole also. To the
extent we become attuned with those ... I think it is both rewarding and educational'.

4. Spiritual Transformative Experience: the powerful impact of voyaging on the lives, perspectives, insights and sense of humanity stemmed from the unexpected and personal experiences during the voyage with natural phenomena, spiritual and cultural connection and the lived experience of sharing, learning and perpetuating the generational knowledge, skills and practices of Oceania's future.

Subthemes
Unexpected
transformation

\section{Theme \#3: Holistic Health and Wellbeing beyond Voyaging}

Description - the experience of voyaging improved holistic health and well-being across multiple dimensions and multiple levels over time. Immersion in the voyaging experience enabled changes to individuals' physical, mental and emotional health, cultural and social interactions, and awareness of and direct influence by the natural environment and spiritual experiences.

Holistic health was frequently discussed, as reflected by five subthemes illustrating the theme's overall complexity and depth. Subthemes include: (1) Overall Wellbeing; (2) Physical Health; (3) Mental and Emotional Health; (4)
Spiritual Connection and (5) Effects of Nature (table 2: theme \#3).

\section{Theme \#4: Spiritual Transformative Experience}

Description - the powerful impact of voyaging on the lives, perspectives, insights and sense of humanity stemmed from the unexpected and personal experiences during the voyage with natural phenomena, spiritual and cultural connection and the lived experience of sharing, learning and perpetuating the generational knowledge, skills and practices of Oceania's future. 
This major theme was expressed by many of the MOs and strongly supported by the remaining MOs who acknowledged that it was one of the most difficult aspects of their individual experiences to articulate. It was particularly difficult to explain it to others who had never voyaged before (ie, to their families or colleagues, etc).

The three subthemes include: (1) Unexpected Transformation; (2) Spiritual Meaning and (3) Experience of Natural Phenomena. Each subtheme was notable for being interrelated but distinct from each other. For example, 'Experience of Natural Phenomena' that occurred while voyaging was an expansive concept in which the individual felt intrinsically attuned with the natural environment, and some seemed to express that experience as an observer while others may have internalised the natural phenomenon as an event with deeper meaning (table 2: theme \#4).

\section{DISCUSSION}

\section{Key findings}

In summary, the four major themes strongly suggest that ocean voyaging aboard a traditional voyaging canoe $\left(w a^{\prime} a\right.$ kaulua) enhanced the health and well-being of the $\mathrm{MO}$ participants. While the experience of ocean voyaging proved to be physically strenuous for many, the overall impact to health and well-being extended beyond any increase in physical exercise. Essentially, traditional Polynesian ocean voyaging provided a cultural-based context for holistic health and well-being that influenced multiple levels and multiple dimensions. Of note, the participants were all experienced physicians serving as MOs whose perceptions of ocean voyaging were deeply personal, unexpected, expansive and life-changing in positive and profound ways. The importance of 'Relationships' is a familiar concept for most physicians; however, the relationships while voyaging extended beyond the individual, to crew members, communities and global populations. As MOs, their role in working alongside their crew mates and tending to their healthcare needs provided additional insights to their contribution as MOs and actually improved their capabilities as physicians. The major theme of 'Preventive Care to Enhance Health' speaks to the increased awareness of functioning on the canoe as well as health preparation to ensure a safe and healthy voyage. The third theme, 'Holistic Health and Wellbeing beyond Voyaging', included the most subthemes (five subthemes) and elicited strong agreement among participants. The multiple dimensions of health/wellbeing included the physical environment (ie, 'Effects of Nature'), cultural environment (ie, 'Spiritual Connection'), behavioural aspects (ie, 'Physical Health' and 'Mental and Emotional Health') and 'Overall Wellbeing', which holistically included physical, mental, emotional and spiritual health. The fourth major theme highlights 'Spiritual Transformative Experience' and describes an intense, transformative experience expressed by many of the MOs that changed their thinking and life perspective.
Remarkably, this was the major theme that was probably the most difficult for many of these highly trained physicians to describe, rationalise or articulate. Yet it was the theme that seemed to provide the most enduring impression of their experience.

\section{Results in context}

The original intent of this study was to understand the potential association between a cultural-based physical activity, traditional Polynesian voyaging, with human health and well-being. Prior literature had previously measured the rigour of hula and other cultural forms of physical activities, and some researchers have even demonstrated clinical outcome improvements. ${ }^{33}$ Given that NHs and Polynesians are disproportionately affected by cardiometabolic health disparities, such as DM, CVD, CVA and obesity, which are mitigated by physical activity and other healthful behaviours (dietary intake, etc), we theorised that ocean voyaging may offer a new approach to reducing many of these chronic health conditions common among NHPIs and other high-risk populations. Our study results suggest that the health benefits of ocean voyaging extended far beyond the physical exertion component of ocean voyaging. The theme of 'Holistic Health and Wellbeing beyond Voyaging' emphasises the influence on multiple dimensions and multiple levels that persisted even after the voyage was complete. The multi-level, multi-dimensional themes that emerged from our qualitative study are closely aligned with the SocioEcological Model (SEM) of health. ${ }^{53}$ Specifically, the SEM describes a model of health that functions along multiple levels of influence, multi-dimensional environments and on which human-environment interactions occur at varying levels of aggregation (individual, families, work, communities or whole populations) ${ }^{53}$ Our major theme of 'Relationships' directly relates to the multiple levels of the SEM, as highlighted in subthemes characterising community, crew, leadership and MO relationships. Similarly, the major theme of 'Holistic Health and Wellbeing beyond Voyaging' includes multiple dimensions of health. From 'Physical', 'Mental and Emotional' to 'Effects of Nature' and 'Spiritual Connection', our findings suggest that ocean voyaging provided multiple human-environment dimensions of health while also contributing to 'Overall Wellbeing' under the major theme of 'Holistic Health and Wellbeing beyond Voyaging'.

Few comparisons of ocean voyaging and health exist in the current literature. Most studies that have examined human health and sailing or voyaging have focused on quantitative measures of biochemical or anthropometric changes, physical performance prevoyaging and postvoyaging aboard motorised ocean vessels or navigated by instruments of technology. ${ }^{54-58}$ We identified a single study that examined quality of life (QOL) improvements among outpatients with severe mental disorders (schizophrenia, affective disorders, etc) after participating in a cruise sailing intervention $(\mathrm{N}=40)$. However, after 1 year of follow-up, most patients returned to baseline 
or reported worsening QOL measures. ${ }^{59}$ Of note, the authors used an intervention which amounted to day sails, in which the boat returned to land after a 5-hour cruise. ${ }^{60}$ Thus, the intervention itself was markedly different compared with Polynesian ocean voyaging in terms of strenuous activity level, immersion in crew duties for all (no one is a passenger) and the cultural context (wa'a kaulua, NH language and culture on board, etc) of sailing a traditional voyaging canoe. Thus, the few studies published on human health and diverse ocean voyages are severely limited by small sample sizes, participant bias, lack of cultural context or traditional voyaging environment, and most were aboard motorised or commercial ocean vessels. Few qualitative studies exist, as most of the published literature has focused on quasi-experimental designs (ie, pre-post) intended to measure physiological or energy expenditure changes while working on various ocean vessels. ${ }^{61-63}$

Our study was interested in learning about the multidimensional relationships between the voyage's cultural context, influenced by the natural environment of 'ocean living', guided by ancestral knowledge of wayfinding and the overall mission of the WWV and its impact on the health and well-being of the human participants. This study extends our understanding of a culturally enriched ocean voyaging experience as perceived by physiciantrained MOs and provides new insight on our understanding of the interaction between Polynesian ocean voyaging and holistic health and well-being.

Few health interventions have proven effective and/ or sustainable among NHPI populations to reverse the disproportionate burden of cardiometabolic conditions that are on the rise around the world, including Oceania. Ocean voyaging provides a novel approach to the prevention of cardiometabolic disparities while enriching the traditional ecological knowledge, cultural practice, customs and values of the diverse populations of Oceania, such as NHPIs, who are one of many populations at increased risk. For NHPIs the implications of having their own ancestral cultural-based activities supported by measurable health benefits is a significant step forward in the battle to reverse health disparities and to build cultural resilience and empowerment to reverse longstanding health inequities.

\section{Strengths and limitations}

A major strength of this qualitative study was the analytical approach that used a systematic Framework Method followed by group member checking of $95 \%$ of the participants to improve the trustworthiness of the data and interpretation of the results. ${ }^{52}$ This is also the first research study to understand the impact of ocean voyaging on human health and well-being, using standardised methods of scientific rigour (ie, Consolidated criteria for Reporting Qualitative Research guidelines) to further understand the socioecological underpinnings of ocean voyaging to human health and well-being. ${ }^{645}$ The opportunity presented by the completion of the WWV was fortuitous in facilitating this study and may provide novel insights to our understanding of the SEM of ocean voyaging as the means to address persistent health inequities among NHPIs and other at risk populations. We acknowledge the study limitation of participant bias posed by interviewing only the MOs in this qualitative study. However, we intentionally chose to select the MOs as astute medical observers with the idea that they might be best positioned to provide the most objective assessment of overall health and well-being of the crew as well as themselves. Future studies to enrol non-MO crew members to compare with this initial study are warranted and would definitely strengthen the scientific rigour.

\section{CONCLUSIONS}

Cultural-based physical activities such as ocean voyaging aboard traditional Polynesian voyaging canoes using wayfinding, traditional non-instrument navigation, and powered only by natural forces was perceived as positively associated with holistic health and overall well-being and has the potential for informing future programmes to promote sustainable health equity for those at increased risk, especially among populations living in Oceania.

\section{Author affiliations}

${ }^{1}$ Native Hawaiian Health, John A. Burns School of Medicine, University of Hawai'i at Mānoa, Honolulu, Hawai'i, USA

${ }^{2}$ Centers for American Indian and Alaska Native Health, Colorado School of Public Health, Aurora, Colorado, USA

${ }^{3}$ School of Nursing \& Dental Hygiene, University of Hawai'i at Mānoa, Honolulu, Hawai'i, USA

${ }^{4}$ Partners in Development Foundation, Honolulu, Hawai'i, USA

${ }^{5}$ Policy Analysis \& System Evaluation, Kamehameha Schools - Kapālama Campus, Honolulu, Hawai'i, USA

${ }^{6}$ Kai Ho`oulu, LLC, Honolulu, Hawai' i, USA

Acknowledgements We acknowledge the efforts of our summer research interns who assisted with various research tasks: Robert K. Bradley (2018) and Julia Chung (2019). We are grateful to So Yung Choi for biostatistical assistance and to Ms. Kimberly Ka'iulani Spencer Tolentino, and Ms. Sheri Koike for their administrative support. Finally, we recognize the ongoing support and encouragement of PVS and the 'Ohana Wa'a (Voyaging Canoe Family) leadership to pursue the completion of this scientific effort.

Contributors MKLMM conceived of and designed the overall study concept, collected data, performed data analysis as core research reviewer, interpreted the collected data and wrote the final paper with full editing contributions from all coauthors. CMM collected data and performed data analysis as core research reviewer and edited, interpreted the results and edited the final paper in collaboration with all coauthors. SAS refined the data analysis, reviewed and interpreted the results and edited the final paper in collaboration with all coauthors. SMK reviewed, edited the collected data and refined the interpretation of the results and edited the final paper in collaboration with all coauthors. CLA reviewed, edited data methods and refined the interpretation and writing of the paper in collaboration with all the authors. HKG reviewed, verified data on the Worldwide Voyage, collected data, performed data analysis as core research reviewer and edited and refined the final version of the paper in collaboration with all coauthors.

Funding This study was supported by financial resources of the Research Division, Department of Native Hawaiian Health, John A. Burns School of Medicine, University of Hawai'i. MKLMM effort was supported in part by the following grant awards: U01DK0484131, P20GM113134.

Competing interests None declared.

Patient consent for publication Not required. 
Ethics approval Due to the 'low risk' nature of this study, it was designated as exempt by the University of Hawai'i, Committee on Human Subjects, IRB 201800934. Nonetheless, we chose to obtain ethical approval directly from participants via written BMJOpen consent form: signed $(n=19)$ or verbal $(n=1$, unavailable for written signature)

Provenance and peer review Not commissioned; externally peer reviewed.

Data availability statement Upon reasonable request, sharing of deidentified and anonymized data will be given full consideration.

Supplemental material This content has been supplied by the author(s). It has not been vetted by BMJ Publishing Group Limited (BMJ) and may not have been peer-reviewed. Any opinions or recommendations discussed are solely those of the author(s) and are not endorsed by BMJ. BMJ disclaims all liability and responsibility arising from any reliance placed on the content. Where the content includes any translated material, BMJ does not warrant the accuracy and reliability of the translations (including but not limited to local regulations, clinical guidelines, terminology, drug names and drug dosages), and is not responsible for any error and/or omissions arising from translation and adaptation or otherwise.

Open access This is an open access article distributed in accordance with the Creative Commons Attribution Non Commercial (CC BY-NC 4.0) license, which permits others to distribute, remix, adapt, build upon this work non-commercially, and license their derivative works on different terms, provided the original work is properly cited, appropriate credit is given, any changes made indicated, and the use is non-commercial. See: http://creativecommons.org/licenses/by-nc/4.0/.

\section{ORCID iD}

Marjorie K Leimomi Mala Mau http://orcid.org/0000-0002-1970-2796

\section{REFERENCES}

1 Sear DA, Allen MS, Hassall JD, et al. Human settlement of East Polynesia earlier, incremental, and coincident with prolonged South Pacific drought. Proc Natl Acad Sci U S A 2020;117:8813-9.

2 Kirch PV. On the road of the winds: an archaeological history of the Pacific Islands before European contact. University of California Press, 2002. https://books.google.com/books?id=H7lwDwAAQBAJ

3 Lewis D. We, the Navigators: the ancient art of Landfinding in the Pacific. University of Hawaii Press, 1994. https://books.google.com/ books?id=SiCCMB6xQJoC

4 Kyselka W. An ocean in mind. University of Hawaii Press, 1987. https://books.google.com/books?id=B1msghbjMbkC

5 Finney BR, Among M, Babayan C. Voyage of rediscovery: a cultural odyssey through Polynesia. University of California Press, 1994. https://books.google.com/books?id=1eEIDQAAQBAJ

6 Kirch PV. On the road of the winds: an archaeological history of the Pacific Islands before European contact. Revised and expanded edition. Oakland, California: University of California Press, 2017.

7 Holmes T. The Hawaiian Canoe, 1993. https://books.google.com/ books? id=WzMHAAAACAAJ

8 Kane HK. Voyagers. WhaleSong, 1993. https://books.google.com/ books?id=fghoHl1AVOUC

9 McGregor DP. Na Kua'aina: living Hawaiian culture. University of Hawai'i Press, 2007. https://www.jstor.org/stable/j.ctt6wr2zc

10 MacKenzie MK. Historical Background. In: Native Hawaiian law : a treatise. Honolulu, Hawai ‘: Kamehameha Publishing, 2015: 5-74.

11 Low S. Hawaiki Rising: Hōküle'a, Nainoa Thompson, and the Hawaiian Renaissance. 1st ed. University of Hawaii Press, 2019. https://books.google.com/books?id=olvGDwAAQBAJ

12 Paglinawan LK, Paglinawan RL, Kauahi D. Nana I Ke Kumu, Helu Ekolu. First edn. Honolulu, Hawai‘i: Liliuokalani Trust, 2020.

13 Panapasa SV, Mau MK, Williams DR, et al. Mortality patterns of native Hawaiians across their lifespan: 1990-2000. Am J Public Health 2010;100:2304-10.

14 Look MA, Soong S, Kaholokula JK. Assessment and priorities for health and well-being in native Hawaiians and Pacific Islanders 2020.

15 Furman A, Shisido SKD, Health NH. In: Native Hawaiian law : a treatise. Honolulu, Hawai 'i: Kamehameha Publishing, 2015: 1306-48.

16 Mau MK, Sinclair Ka'imi, Saito EP, et al. Cardiometabolic health disparities in native Hawaiians and other Pacific Islanders. Epidemiol Rev 2009;31:113-29.

17 Mau MK, West MR, Shara NM, et al. Epidemiologic and clinical factors associated with chronic kidney disease among Asian Americans and native Hawaiians. Ethn Health 2007;12:111-27.

18 Nakagawa K, Koenig MA, Seto TB, et al. Racial disparities among native Hawaiians and Pacific Islanders with intracerebral hemorrhage. Neurology 2012;79:675-80.
19 Braun KL, Yang H, Look MA, et al. Age-Specific Native Hawaiian mortality: a comparison of full, part, and Non-Hawaiians. Asian Am Pac IsI J Health 1996;4:352-62.

20 Grandinetti A, Chang HK, Chen R, et al. Prevalence of overweight and central adiposity is associated with percentage of Indigenous ancestry among native Hawaiians. Int J Obes Relat Metab Disord 1999;23:733-7.

21 Zhu Y, Sidell MA, Arterburn D, et al. Racial/Ethnic disparities in the prevalence of diabetes and prediabetes by BMI: patient outcomes research to advance learning (portal) multisite cohort of adults in the U.S. Diabetes Care 2019;42:2211-9.

22 Okihiro M, Davis J, White L, et al. Rapid growth from 12 to 23 months of life predicts obesity in a population of Pacific island children. Ethn Dis 2012;22:439-44.

23 Novotny R, Oshiro CES, Wilkens LR. Prevalence of childhood obesity among young multiethnic children from a health maintenance organization in Hawaii. Child Obes 2013;9:35-42.

24 Aluli NE. Prevalence of obesity in a native Hawaiian population. Am J Clin Nutr 1991;53:1556S-60.

25 Minster RL, Hawley NL, Su C-T, et al. A thrifty variant in CREBRF strongly influences body mass index in Samoans. Nat Genet 2016;48:1049-54.

26 Sun H, Lin M, Russell EM, et al. The impact of global and local Polynesian genetic ancestry on complex traits in Native Hawaiians. PLoS Genet 2021;17:e1009273.

27 Knowler WC, Barrett-Connor E, Fowler SE, et al. Reduction in the incidence of type 2 diabetes with lifestyle intervention or metformin. N Engl J Med 2002;346:393-403.

28 Mau MK, Keawe'aimoku Kaholokula J, West MR, et al. Translating diabetes prevention into native Hawaiian and Pacific Islander communities: the PILI 'Ohana Pilot project. Prog Community Health Partnersh 2010;4:7-16.

29 Kaholokula JK, Wilson RE, Townsend CKM, et al. Translating the Diabetes Prevention Program in Native Hawaiian and Pacific Islander communities: the PILI 'Ohana Project. Trans/ Behav Med 2014;4:149-59.

30 Albright C, Mau M, Choy L. Physical Activity among Native Hawaiians and Pacific Islanders. In: Physical activity in diverse populations: evidence and practice. Taylor \& Francis, 2017: 123-42.

31 Bopp M. Introduction to Physical Activity and Health Disparities. In: Physical activity in diverse populations: evidence and practice. Taylor \& Francis, 2017: 1-12.

32 Usagawa T, Look M, de Silva M, et al. Metabolic equivalent determination in the cultural dance of hula. Int J Sports Med 2014;35:399-402.

33 Kaholokula Joseph Keawe'aimoku, Look M, Mabellos T, et al. Cultural dance program improves hypertension management for native Hawaiians and Pacific Islanders: a pilot randomized trial. $J$ Racial Ethn Health Disparities 2017;4:35-46.

34 Holmes T. The Hawaiian canoe. Honolulu: Editions Limited, 1993.

35 Ingersoll KA. Waves of knowing: a seascape Epistemology. Duke University Press, 2016.

36 Kane HK. Voyagers. Captain Cook, Hawai‘i: Kawainui Press, 2005.

37 Kyselka W. An ocean in mind. Honolulu: University of Hawaii Press 1987

38 Lewis D. We, the navigators: the ancient art of landfinding in the Pacific. 2nd ed. Honolulu: University of Hawaii Press, 1994.

39 Low S. Hawaiki Rising: Hokule'a, Nainoa Thompson, and the Hawaiian Renaissance. First American Edition edition. Island Heritage Publishing, 2013.

40 Allen J. Malama Honua: Hokule'a - A Voyage of Hope. 1st Edition. Ventura, CA: Patagonia, 2017.

41 Kana'iaupuni S. We voyage for the earth: Cultural advantage as a global education framework. In: Handbook of Indigenous education. Springer Publications, 2018: 1137-63.

42 Aiu PK. Health care aboard the Hokulea--energy requirement study. Hawaii Med J 1994;53:53.

43 Shehata CL, Anthony Na'alehu, Maskarinec GG. Maintaining balance for a long voyage. Pac Health Dialog 2007;14:213-7.

44 Shehata C, Anthony Na'alehu, Maskarinec GG. "Navigating Change." A Voyage to Connect Science and Culture with Health. Californian J Health Promot 2005;3:134-43.

45 Rothe JP, Ozegovic D, Carroll LJ. Innovation in qualitative interviews: "Sharing Circles" in a First Nations community. Inj Prev 2009;15:334-40.

46 Affonso DD, Shibuya JY, Frueh BC. Talk-story: perspectives of children, parents, and community leaders on community violence in rural Hawaii. Public Health Nurs 2007;24:400-8.

$47 \mathrm{SQ}$ Q, Dumay J. The qualitative research interview. Qualitative Research in Accounting \& Management 2011;8:238-64. 
48 Gale NK, Heath G, Cameron E, et al. Using the framework method for the analysis of qualitative data in multi-disciplinary health research. BMC Med Res Methodol 2013;13:117.

49 Paulus T, Lester J, Dempster P. Digital tools for qualitative research. London, United Kingdom: SAGE Publications Ltd, 2014.

50 Saldana J. The coding manual for qualitative researchers. SAGE, 2012.

51 Boeije H. Boeije H. a purposeful approach to the constant comparative method in the analysis of qualitative interviews. Quality and Quantity 2002;36:391-409.

52 Tracy SJ. Qualitative Quality: Eight “Big-Tent” Criteria for Excellent Qualitative Research. Qualitative Inquiry 2010;16:837-51.

53 Glanz K, Rimer BK, Lewis FM. Health behavior and health education: theory, research, and practice. 3rd ED. Jossey-Bass, 2002. https:// books.google.com/books?id=wZ5pAAAAMAAJ

54 Bilzon JLJ, Scarpello EG, Smith CV, et al. Characterization of the metabolic demands of simulated shipboard Royal Navy fire-fighting tasks. Ergonomics 2001;44:766-80.

55 Heus R, Wertheim AH, Havenith G. Human energy expenditure when walking on a moving platform. Eur J Appl Physiol 1998;77:388-94.

56 Gray G, Matheson G, McKenzie D. The metabolic cost of two kayaking techniques. Int J Sports Med 1995;16:250-4.

57 Pendergast D, Zamparo P, di Prampero PE, et al. Energy balance of human locomotion in water. Eur J Appl Physiol 2003;90:377-86.
58 Felici F, Rodio A, Madaffari A, et al. The cardiovascular work of competitive dinghy sailing. J Sports Med Phys Fitness 1999;39:309.

59 Carta MG, Maggiani F, Pilutzu L, et al. Sailing can improve quality of life of people with severe mental disorders: results of a cross over randomized controlled trial. CPEMH 2014;10:80-6.

60 Carta MG, Maggiani F, Pilutzu L, et al. Sailing for rehabilitation of patients with severe mental disorders: results of a cross over randomized controlled trial. CPEMH 2014;10:73-9.

61 Bernardi M, Quattrini FM, Rodio A, et al. Physiological characteristics of America's Cup sailors. J Sports Sci 2007:25:1141-52.

62 Lu Y, Gao Y, Cao Z, et al. A study of health effects of long-distance Ocean voyages on seamen using a data classification approach. BMC Med Inform Decis Mak 2010;10:13

63 Bernardi E, Delussu SA, Quattrini FM, et al. Energy balance and dietary habits of America's Cup sailors. J Sports Sci 2007;25:1153-60.

64 Tong A, Sainsbury P, Craig J. Consolidated criteria for reporting qualitative research (COREQ): a 32-item checklist for interviews and focus groups. Int J Qual Health Care 2007;19:349-57.

65 O'Brien BC, Harris IB, Beckman TJ, et al. Standards for reporting qualitative research: a synthesis of recommendations. Acad Med 2014;89:1245-51. 